\title{
A identidade formativa do professor de Matemática de escolas rurais
}

\section{The formative identity of Mathematics Teachers in rural schools}

\author{
Marcos Guilherme Moura-Silva ${ }^{1}$ \\ https://orcid.org/0000-0003-3589-1897 \\ Tadeu Oliver Gonçalves ${ }^{2}$ \\ https://orcid.org/0000-0002-2704-5853 \\ Carlos Alberto Gaia Assunção ${ }^{1}$ \\ https://orcid.org/0000-0002-1849-5094
}

\begin{abstract}
Resumo: O estudo objetiva estabelecer uma compreensão holística sobre identidade formativa de professores que ensinarão matemática em contextos de educação rural, discutindo aspectos da constituição dessa identidade no âmbito das Licenciaturas em Educação do Campo, reconhecidas por formar educadores para os espaços rurais brasileiros. Como método, pautamo-nos nos procedimentos da Análise Textual Discursiva de Roque Moraes e Maria do Carmo Galiazzi, tendo como corpus de análise documentos e outros materiais produzidos sobre o tema que direcionam a graduação desses professores. Os resultados categorizam a constituição dessa identidade a partir de quatro fatores específicos: fator formativo (ou institucional), contextual, matemático e sociopolítico, sendo este último aquele com maior proeminência e impacto identitário. Trata-se, portanto, de uma identidade não apenas pedagógica e restrita ao ambiente escolar, mas fortemente integrada às questões políticas e sociais relativas ao campo, onde se buscam as interligações com o saber matemático acadêmico.
\end{abstract}

Palavras-chave: Formação inicial do professor. Ensino de matemática. Escola rural. Educação no campo. Educação rural.

\begin{abstract}
This study aims to establish a holistic understanding about the formative identity of teachers who will teach mathematics in rural education contexts by addressing aspects of the constitution of this identity within the scope of the Degree in Education in the Countryside, recognized for preparing educators for Brazilian rural areas. As for the method, we have used the procedures of Discursive Textual Analysis, and the corpus of analysis consisted of documents and other materials produced on the subject that steer the education of these teachers. The results categorize the constitution of this identity based on four specific factors: formative (or institutional), contextual, mathematical and sociopolitical factors, the last one being the one with the greatest prominence and impact on identity. It is, therefore, an identity which is not only pedagogical and restricted to the school environment, but strongly integrated to the political and social issues related to the field, where the interconnections with academic mathematical knowledge are sought.
\end{abstract}

Keywords: Teacher initial education. Mathematics teaching. Rural schools. Teacher initial education. Rural education.

\footnotetext{
${ }^{1}$ Universidade Federal do Sul e Sudeste do Pará (UNIFESSPA), Marabá, PA, Brasil. E-mail: guilhermemoura@ unifesspa.edu.br.

${ }^{2}$ Universidade Federal do Pará (UFPA), Belém, PA, Brasil.
} 


\section{Introdução}

Nas duas últimas décadas, as investigações sobre identidade do professor ganharam destaque nas pesquisas em Educação. Beauchamp e Thomas (2009) fornecem uma visão geral da literatura sobre identidade docente, destacando os vários enfoques como o tema vem sendo abordado. Por exemplo, a partir da "reinvenção de si mesmo" (MITCHELL; WEBER, 1999), em termos das narrativas criadas por professores para explicar sua vida profissional (CONNELLY; CLANDININ, 1999; SFARD; PRUSAK, 2005), a partir das metáforas que guiam e produzem compreensões sobre o papel do professor (HUNT, 2006; LEAVY; MCSORLEY; BOTÉ, 2007), e a influência de uma ampla gama de fatores contextuais sobre os professores e suas práticas (CHEVRIER et al., 2007). Algumas pesquisas também vêm explorando a temática sobre identidade docente considerando aqueles que estão em serviço ou em formação inicial e aqueles que se relacionam com uma disciplina específica, como a Matemática, por exemplo (DRAKE; SPILLANE; HUFFERD-ACKLES, 2001; HOBBS, 2012).

Assim, três categorias principais podem ser definidas a partir do que vem sendo discutido na literatura, conforme Beauchamp e Thomas (2009): (1) formação e desenvolvimento de identidade dos professores; (2) características da identidade docente; e, (3) identidade docente considerando suas histórias de vida. Este estudo se situa na categoria 1, no que diz respeito à formação e ao desenvolvimento da identidade docente, considerando o processo formativo inicial de professores de matemática para escolas rurais ${ }^{3}$. Por se tratar da constituição identitária de futuros professores, adotaremos no escopo do texto a expressão identidade formativa com significado similar ao que entenderemos por identidade docente, buscando evidenciar elementos dessa formação que podem influenciar o ser professor de matemática no/para o campo.

A esse respeito, sabemos que os futuros professores em processo de formação inicial passam por uma mudança de identidade formativa/discursiva/profissional (GEE, 2000) ao longo de seus percursos formativos. Essa mudança é contínua e, por vezes, dramática quando eles assumem a docência nos distintos e desafiadores contextos de ensino escolar. Compreender os fatores da constituição dessa identidade do professor em formação nos cursos de Licenciatura em Educação do Campo, portanto, pode contribuir nas formas como essas licenciaturas são construídas, servindo como lente analítica capaz de examinar vários aspectos do ensino e da prática educacional, inclusive como elemento organizador da vida profissional.

O desconhecimento de estudos que investigaram a identidade formativa do professor de matemática de escolas rurais nos moveu a refletir em torno do tema, de modo que estamos interessados em promover uma discussão sobre como essa identidade é constituída no contexto da formação inicial desses sujeitos a partir do que se conhece sobre elas e, ao mesmo tempo, auxiliar a comunidade científica na projeção de programas e ações formativas.

\footnotetext{
${ }^{3}$ Visando a objetividade do texto em relação ao tema principal abordado (identidade docente) e a padronização do termo em relação aos estudos internacionais, para o escopo desse artigo não adentraremos na discussão teórica que difere as expressões educação rural e educação do campo, que serão consideradas sinônimas.
} 


\section{Pressupostos teórico-conceituais sobre identidade docente}

Ainda que amplamente discutido em vários cenários de investigação, ressalta-se que o conceito de identidade docente é permeado por múltiplas perspectivas teóricas, que, por vezes, funcionam como obstáculos para um estudo profícuo nesse campo de inquérito (BEIJAARD; MEIJER; VERLOOP, 2004; BEAUCHAMP; THOMAS, 2009).

Uma compreensão abrangente desse conceito resume a noção de identidade do professor como o quem somos que se desenvolve em nossas próprias mentes e nas mentes dos outros (HARALAMBOS; HOLBORN, 2000). Teoricamente, essa conceituação se baseia na perspectiva sociocultural, como a informada nos estudos sobre trabalho e aprendizagem situada, em comunidades de prática - amplamente discutida em Wenger (1998) -, além dos conceitos de discurso e poder. Nessas perspectivas, o desenvolvimento da identidade docente ocorre em comunidades de práticas levando em consideração o contexto e o discurso (BENNISON, 2015; ESSIEN, 2014; HODGEN; ASKEW, 2007; HODGES; CADY, 2012; VAN ZOEST; BOHL, 2005), sendo compreendida, portanto, como uma identidade que caracteriza o professor a um grupo social, por meio do qual ele assume papéis, valores e normas.

No intuito de conciliar a variedade de perspectivas sobre identidade docente, encontramos em Gee (2000) uma síntese sobre as principais tendências conceituais que vêm sendo utilizadas nas pesquisas da área. Sua proposição engloba quatro aspectos da formação de identidade, mostrando como ela é formada e sustentada. Embora separadas, é crucial perceber que esses aspectos coexistem de maneira importante e complexa (quadro 1).

Quadro 1 - Quatro maneiras de ver a identidade

\begin{tabular}{|l|l|l|l|}
\hline \multicolumn{2}{|c|}{ Processo } & \multicolumn{1}{c|}{ Legitimado } & Fonte da legitimação \\
\hline Identidade natural: um estado & Desenvolvido por & Forças & Naturais \\
\hline Identidade institucional & Autorizado por & Autoridades & Dentro de instituições \\
\hline $\begin{array}{l}\text { Identidade do discurso: uma } \\
\text { característica individual }\end{array}$ & Reconhecido no & Discurso/Diálogo & $\begin{array}{l}\text { De/com indivíduos } \\
\text { "racionais" }\end{array}$ \\
\hline Identidade de afinidade: experiências & Compartilhado em & Práticas & De grupos de afinidade \\
\hline
\end{tabular}

Fonte: Gee (2000).

Gee (2000) identifica quatro maneiras pelas quais a identidade pode ser percebida: identidade natural, identidade institucional, identidade do discurso e identidade de afinidade, revelando sua natureza multifacetada e mutável em termos das influências contextuais. Em uma primeira perspectiva, somos o que somos principalmente pelas nossas naturezas, enfatizando nossas características biológicas humanas. A legitimação desse tipo de identidade provém da natureza e não da construção social. Na segunda perspectiva, somos o que somos pelas posições que ocupamos na sociedade. Trata-se de uma identidade prescrita em um ambiente institucional estruturado. A legitimidade desse tipo de identidade pode advir de títulos ou um símbolo obrigatório. Em uma terceira perspectiva, somos o que somos pelas nossas realizações individuais interagidas e reconhecidas por outros. Nesse modelo de identidade, enfatiza-se o importante papel do 
discurso. É essa negociação discursiva, influenciada por fatores culturais e sociais que legitima essa identidade. Na quarta perspectiva, somos o que somos pelas experiências vivenciadas em certos grupos de prática (ou grupos de afinidade). Trata-se de uma identidade por afinidade, que passa a ser criada e mantida através da partilha e da participação em comunidades de prática.

Adotamos como lente analítica sobre identidade docente a perspectiva teórica de Gee (2000), por ela reunir as principais vertentes conceituais acerca do tema, abrangendo aspectos sociais, contextuais e institucionais que interessam para os propósitos de nosso estudo. Como informado anteriormente, a expressão identidade formativa se refere à identidade do professor em formação, estando em consonância ao que estamos entendendo por identidade docente.

\section{Procedimentos metodológicos}

No intuito de alcançarmos o objetivo delineado, ancoramo-nos na Análise Textual Discursiva de Moraes e Galiazzi (2011, p. 17). Conforme os autores, esse processo perpassa pela delimitação de um corpus de análise a partir de "um conjunto [de documentos] capazes de produzir resultados válidos e representativos". Em seguida, realiza-se um movimento de desconstrução interpretativa desses documentos, permitindo "novas compreensões em relação aos fenômenos investigados" (MORAES; GALIAZZI, 2011, p. 21).

Nosso corpus de análise se constituiu a partir dos documentos oficiais que direcionam as diversas Licenciaturas em Educação do Campo no Brasil, incluindo suas resoluções e seus projetos políticos pedagógicos, artigos publicados sobre essa licenciatura com enfoque na formação do professor de Matemática do campo e aqueles relacionados à identidade docente. Ressalta-se que, dada sua recente implementação, existem poucos estudos divulgados discutindo a especificidade dessa licenciatura, razão pela qual nossas análises ficaram limitadas aos referenciais existentes.

\section{Discussão}

Pautados em tais pressupostos e considerando os aspectos que vêm sendo discutidos nos estudos sobre identidade docente, categorizamos a posteriori quatro fatores considerados determinantes na constituição dessa identidade: fator formativo (ou institucional), fator contextual, fator sociopolítico e fator matemático.

O fator formativo envolve uma contextualização de como está ocorrendo a formação inicial de professores de Matemática para escolas rurais em Instituições de Ensino Superior (IES). Essa análise será baseada em documentos oficiais, principalmente no que diz respeito à estrutura dos projetos políticos pedagógicos de cursos de Licenciatura em Educação do Campo.

O fator contextual envolve a compreensão acerca dos espaços onde os professores do campo atuam ou atuarão. Por entendermos que o contexto de trabalho tem forte influência na constituição identitária do professor, discutiremos acerca de suas condições e restrições.

O fator sociopolítico abrangerá uma característica dos professores das escolas do campo, referindo-se aos seus engajamentos em lutas históricas por direitos e reconhecimentos. 
A esse propósito, ressalta-se que muitos desses professores têm relações diretas com movimentos sociais organizados - sendo, portanto, um fator determinante na constituição de suas identidades formativas e profissionais.

Por último, e não menos importante, o fator matemático busca compreender a relação dos professores do campo em formação com os conhecimentos escolares e curriculares de Matemática. A reflexão perpassa por uma preocupação didática e pelo capital escolar (matemático) trazido por esses graduandos - que, por vezes, são limitados e construídos em uma Educação Básica Multissérie ${ }^{4}$ - e através de um Ensino Médio Modular ${ }^{5}$ - procurando analisar como os conhecimentos matemáticos são mobilizados nas Licenciaturas em Educação do Campo com habilitação em Matemática e o impacto disso na identidade dos professores em formação.

\section{Fator formativo}

Para tratarmos desse fator específico, convém rememorarmos, brevemente, sobre o contexto em que o curso de Licenciatura em Educação do Campo no Brasil foi criado, para, na sequência, discutirmos alguns elementos de seus Projetos Políticos Pedagógicos (PPP) no que diz respeito à constituição da identidade desses professores.

A política nacional por uma Educação do Campo nasce de ações no Ministério de Educação (MEC) iniciadas em 2003, marcadas fortemente pela atuação de movimentos sociais organizados. A expressão do campo é utilizada para “designar um espaço geográfico e social que possui vida em si e necessidades próprias, como parte do mundo e não aquilo que sobra além das cidades" (INEP, 2007, p. 8).

O campo é concebido enquanto espaço que tem identidade cultural própria e práticas compartilhadas, socializadas por aqueles que ali vivem. Essa agenda pública nacional vinha sendo formulada/implantada pela Secretaria de Educação Continuada, Alfabetização e Diversidade (SECAD), subordinada à Coordenação Geral de Educação do Campo (CGED) e do Grupo de Trabalho Permanente de Educação do Campo (GPT).

A observação ao perfil dos professores que atendem as escolas do campo foi peça importante no argumento de fortalecimento dessa política nacional. No censo do Instituto Nacional de Estudos e Pesquisas Educacionais Anísio Teixeira (Inep) divulgado em 2009 pode-se notar que o percentual de docentes que atuam nas séries finais do Ensino Fundamental de escolas rurais com apenas o Ensino Médio completo correspondia a 46,7\% do total, conforme Gráfico 1.

\footnotetext{
${ }^{4}$ Processo educativo onde o professor trabalha, simultaneamente, com várias séries (anos escolares), atendendo alunos com diferentes idades e níveis de conhecimento.

${ }^{5}$ Trata-se de um sistema de ensino alternativo ao convencional, com uma organização curricular agrupada por módulos que visa otimizar a oferta de disciplinas escolares em locais de difícil acesso.
} 
Gráfico 1 - Percentual de docentes que atuam nas séries finais ( $5^{a}$ a $8^{a}$ série) do Ensino Fundamental por grau de formação e localização (urbana e rural)

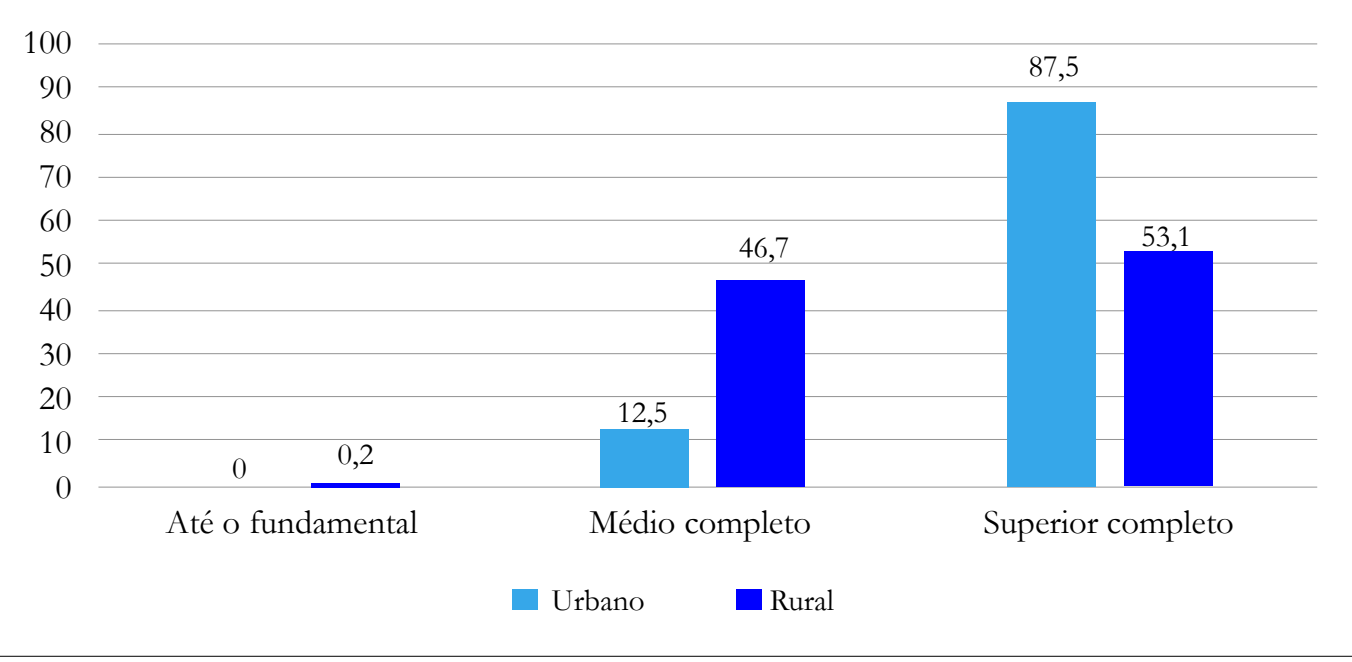

Fonte: Inep (2007).

Isso representava quase a metade de professores dito leigos, sem formação em nível superior, que deveriam promover uma educação com características e demandas próprias. Ao se ampliar essa análise para o exercício da docência no Ensino Médio, percebeu-se que 11,3\% das funções docentes nesse nível de ensino eram exercidas por profissionais que atuavam no nível de ensino correspondente à sua escolaridade (INEP, 2007).

Foi nesse contexto de extrema precariedade formativa que cursos de graduação em nível superior para educadores do Campo foram criados - como as Licenciaturas em Educação do Campo. Tais cursos nasceram com a missão de mitigar essas condições de carência quanto à qualificação docente e ao mesmo tempo adequar uma organização curricular e metodológica para a realidade das escolas do campo. Ao menos 65 IES tiveram graduações com esse perfil aprovado. Destas, 25 cursos tinham habilitação em Matemática ou em Ciências da Natureza e Matemática (SACHS; ELIAS, 2016).

De maneira geral, os projetos político-pedagógicos desses cursos trazem em sua essência a preparação de educadores para uma atuação profissional em comunidades rurais, observando os contextos escolar, social e político. Parte-se do ideário de que o território e as territorialidades das populações e comunidades do campo devem guiar as práticas docentes.

Nessa lógica, entende-se que o tronco curricular, composto pelos elementos da formação básica, da formação específica e da formação integradora, é o caminho ou percurso formativo idealizado para ser seguido na constituição de um educador do campo. Esse tronco tem raízes em movimentos sociais e precisa de uma terra para ser germinado - nesse caso, a universidade ocupa esse papel.

O elemento que promove a interligação entre as raízes (universidade e movimentos sociais) e as folhas (Educação do Campo) constitui o tronco, propriamente dito, formado por tempos e espaços de formação que definem as três composições formativas, aqui denominados 
núcleos de formação - formação básica comum, formação específica em uma das quatro áreas de conhecimento: Matemática, Ciências da Vida e da Natureza, Ciências Sociais e Humanidades, Línguas, artes e literatura - interligadas pelo eixo temático: Educação do Campo, e formação integradora que visa estratégias pedagógicas multidisciplinares em sintonia direta com as comunidades rurais.

Os cursos são desenvolvidos em dois tempos: Tempo Escola e Tempo Comunidade em uma perspectiva de alternância pedagógica. O tempo escola se desenvolve na Universidade. O tempo comunidade é desenvolvido nos locais de moradia/trabalho dos educandos. Tal dinâmica constitui tempos de estudos teóricos e práticos, em que essa alternância "assume no curso o sentido de comunidade como um espaço físico, social e político, como dimensão formativa" (ANTUNES-ROCHA, 2009, p. 50).

Os alunos dessas licenciaturas realizam seus estágios de docência vinculados às pesquisas socioeducacionais que, por sua vez, são transversalizadas por eixos temáticos, como Histórias de vida, Saberes da docência, Cultura e Trabalho, todos relacionados a contextos campesinos. Os relatórios e os achados dessas pesquisas socioeducacionais são socializados no tempo universidade, em caráter crítico-reflexivo. Johnston (2015) enfatiza o papel da socialização na construção da identidade do professor e Cattley (2007) encontrou ligações entre a escrita reflexiva e a formação de identidade, sugerindo a importância desse processo na constituição formativa desses professores.

Com efeito, o fator formativo, nos termos postos, traz imbricações importantes para a identidade formativa do professor que ensina/ensinará matemática nas escolas do campo. Percebe-se um incentivo para intervir de maneira crítica e efetiva na realidade das comunidades rurais. Nesse propósito, nota-se que este é o meio e o caráter principal da formação desses professores. Os conhecimentos pedagógicos devem ser mobilizados de maneira multidisciplinar e no protagonismo das práticas socioculturais, no chão das lutas dos camponeses e no pano de fundo de suas histórias de vida. Nos termos de Gee (2000, p. 102, tradução nossa), podemos situar o fator formativo das Licenciaturas em Educação do Campo como constitutivo de uma identidade institucional, uma vez que está centrado "em leis, regras, tradições e princípios" próprios, como mencionados anteriormente, e conduzem a uma formação multidisciplinar e peculiar em seus modos de organização; além de uma identidade por afinidade, relacionada ao "acesso e participação em práticas específicas que fornecem experiências necessárias a cada um dos membros do grupo" (GEE, 2000, p. 105, tradução nossa), como por exemplo, pesquisas socioeducacionais e os processos de alternância pedagógica - esta última capaz de estabelecer interações entre teoria (tempo universidade) e prática (tempo comunidade). Tratase de uma identidade não apenas pedagógica e centrada no ambiente escolar, mas conectada fortemente com as práticas presentes nas comunidades rurais.

\section{Fator contextual}

Vários estudos vêm mostrando que os fatores contextuais (incluindo o contexto dos objetos de saber) influenciam a construção da identidade docente e seu desenvolvimento profissional (FREITAS, 2008; DRAKE; SPILLANE; HUFFERD-ACKLES, 2001; GOOS; BENNISON, 2008; HOBBS, 2012; LUTOVAC; KAASILA, 2014; OWENS, 2014). Particularmente, alguns deles enfatizam o papel disciplinar e o nível educacional em que os 
professores ensinam matemática como influenciadores da construção de suas identidades (DRAKE; SPILLANE; HUFFERD-ACKLES, 2001; KASTEN; AUSTIN; JACKSON, 2014; LEATHAM; HILL, 2010). Por exemplo, Hobbs (2012) discutiu como as abordagens de ensino do professor são modeladas a partir de seus contextos de atuação.

No caso específico do professor que ensina Matemática no campo, esse fator contextual é altamente determinante de suas práticas pedagógicas e certamente influencia sua relação com o saber, os tempos e os espaços de ensino. Visando uma melhor abordagem, vamos compartimentar essa discussão em três subfatores: o contexto em relação à organização escolar, o contexto em relação à infraestrutura escolar e o contexto em relação ao currículo das escolas rurais.

Em relação ao primeiro - organização escolar -, os educadores que atuam ou atuarão nas escolas do campo lidam com uma característica ainda recorrente e singular nesses educandários: a presença de classes multisseriadas. O censo escolar divulgado em 2007, um dos últimos publicados, mostrou que $59 \%$ das escolas do meio rural eram formadas exclusivamente por turmas multisseriadas ou unidocentes, além de turmas seriadas e mistas (Tabela 1).

Tabela 1 - Formas de organização escolar das escolas do campo

\begin{tabular}{lcccc}
\hline \multirow{2}{*}{ Forma de organização } & \multicolumn{2}{c}{ Estabelecimento } & \multicolumn{2}{c}{ Matrícula } \\
& $\mathbf{2 0 0 2}$ & $\mathbf{2 0 0 5}$ & $\mathbf{2 0 0 2}$ & $\mathbf{2 0 0 5}$ \\
\hline Ensino Fundamental - 1. ${ }^{\mathrm{a}}$ a 8. ${ }^{\mathrm{a}}$ série & 100.967 & 90.413 & 6.236 .447 & 5.799 .387 \\
Exclusivamente multisseriada & 61.927 & 53.700 & 1.681 .562 & 1.371 .930 \\
Exclusivamente seriada & 19.455 & 18.446 & 3.035 .459 & 2.986 .209 \\
Mista (multisseriada e seriada) & 19.585 & 18.267 & 1.519 .426 & 1.441 .248 \\
\hline
\end{tabular}

Fonte: INEP (2007).

As classes multisseriadas são formadas por alunos de diferentes idades e anos escolares em uma mesma sala de aula. A unidocência diz respeito ao único professor que é responsável pela atuação pedagógica de uma classe multisseriada. Os professores que atuam em escolas com esse tipo de organização por vezes acumulam tarefas administrativas e de zeladoria voltadas para a manutenção da unidade escolar (INEP, 2007); isso certamente tem impacto na condução de suas atividades didáticas. A taxa de distorção idade - ano escolar é sempre maior em escolas de áreas rurais em detrimento das áreas urbanas, favorecerendo/derivarando essas classes multisseriadas (BRASIL, 2008).

No que diz respeito às características físicas e disponibilidade de infraestrutura, notase uma discrepância em relação àquelas observadas em escolas urbanas, salvo raras exceções. Conforme o gráfico 2, o contexto de trabalho dos professores do campo é ausente de bibliotecas, laboratórios de informática, laboratórios de ciências e quadras de esporte, por exemplo.

No que se refere ao contexto curricular nota-se ainda uma predominância de um currículo advindo das escolas urbanas (urbanocêntrico), muito embora a construção de um currículo mais voltado à realidade rural está sendo um movimento em vias de construção. 
Gráfico 2 - Percentual de estabelecimentos que oferecem o Ensino Fundamental segundo as dependências disponíveis na escola

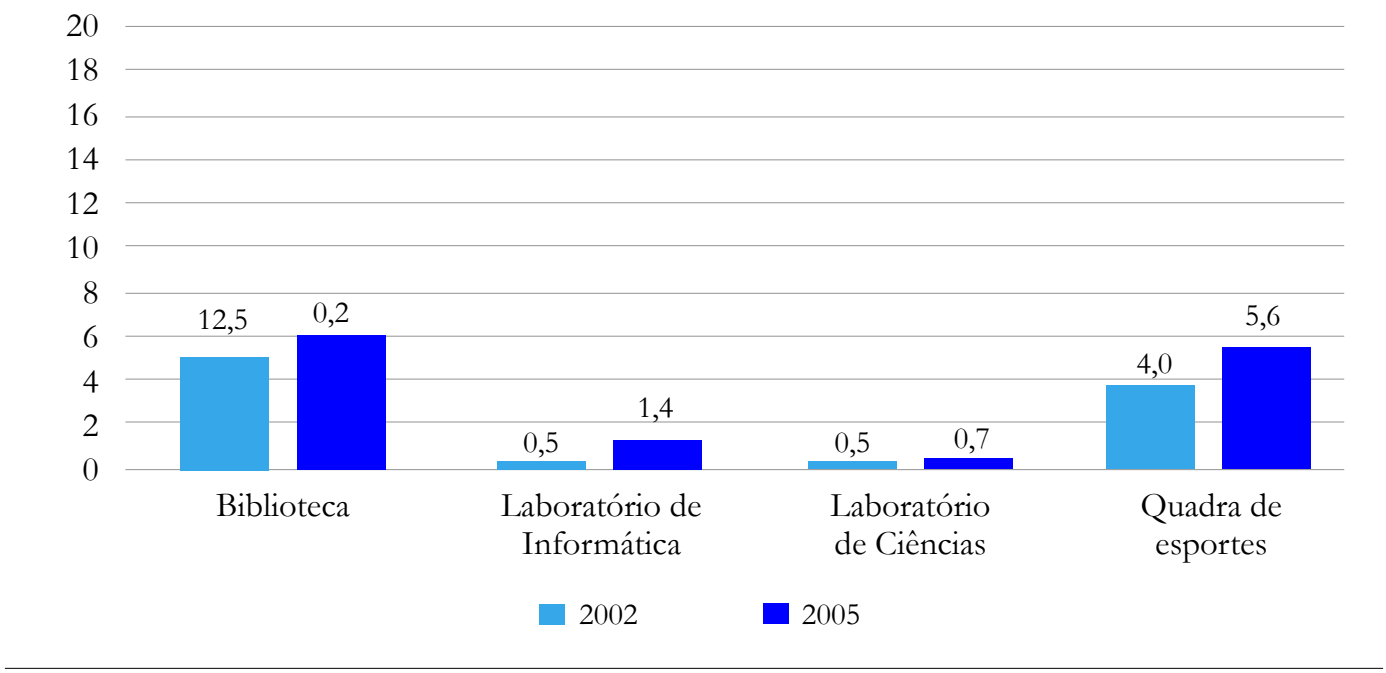

Fonte: INEP (2007).

Os discentes da Licenciatura em Educação do Campo estudam esses contextos em seus estágios de docência durante o tempo universidade, em uma dinâmica de pesquisa-ação. Trata-se de uma máxima do projeto formativo dessa licenciatura, que busca colocar seus educandos, desde os primeiros semestres, em diálogo com a comunidade, em um movimento de observação-intervenção.

Essa imbricação com o futuro contexto de atuação profissional é determinante na identidade desses professores (VAN ZOEST; BOHL, 2005). Não por acaso, nos momentos de socialização que constam na estrutura curricular dessas licenciaturas, os futuros professores tecem críticas, geram relatórios, narram suas experiências e questionam práticas - sinalizando transformações em suas perspectivas de docência, sejam em direção às mudanças ou na manutenção do que experienciaram.

\section{Fator sociopolítico}

O campo é um território de conflitos, sejam sociais, econômicos, ambientais ou agrários. Por esse fato, é comum encontrarmos distintos movimentos sociais organizados cujas ações acabam por reverberar no próprio ato pedagógico. Muitas dessas organizações sociais têm demandas que são articuladas, pautadas e incorporadas às práticas acadêmicas de ensino, pesquisa e extensão nas universidades. Tais articulações geram conexões e configurações institucionais, imprimindo nos sujeitos em formação uma identidade que, nos termos de Gee (2000), podem ser categorizadas como uma identidade discursiva. Isto é, alguns cursos de Licenciatura em Educação do Campo, ao acolherem e carregarem na seiva de sua subjetividade 
pedagógica a responsabilidade vinculativa com questões sociopolíticas, posicionam-se como apoiadores dos movimentos sociais e defensores dessa causa, influenciando e forjando essa identidade discursiva através de suas normatizações e regulações institucionais.

Contudo, as regulações institucionais estão sempre vinculadas às ações políticas e ações políticas que regulam a vida social. Por uma observação em perspectiva, podemos dizer que essa problemática sociopolítica, no campo formativo, é regulada e/ou reguladora. É reguladora quando tais licenciaturas deixam em segundo plano o sistema didático do processo escolar de ensino básico em detrimento da militância política. É regulada, quando apenas o exercício da militância política não é suficiente para melhoria do ensino nas escolas do campo.

Embora Gee (2000, p. 103, tradução nossa) considere que a identidade discursiva não seja "sancionada ou sustentada pelas instituições, mas pelas palavras e ações reconhecidas por atores não oficiais dessas instituições", nosso entender sobre identidade discursiva vai além da concepção defendida por esse autor, pois consideramos que a formação inicial do sujeito nos cursos de Licenciaturas em Educação do Campo é imbuída de/construída por fatores que decorrem do processo político e sociocultural, ocorrendo na interação entre o sujeito e a instituição, ou seja, em um processo dinâmico e dialético marcado pelas interfaces entre demandas sociais e individuais do sujeito e as normatizações institucionais que gerenciam esse processo de interação. Portanto, a identidade discursiva para esses professores em formação é sociopolítica, de modo que, além de ser reconhecida por atores não oficiais e por palavras e ações, é também legitimada por essas instituições que ofertam o curso de Licenciatura em Educação do Campo, incluindo em seus projetos político-pedagógicos eixos temáticos relativos aos conflitos sociais, agrários, ambientais e econômicos.

\section{Fator matemático}

Este é o fator principal que diferencia a identidade docente de termos genéricos, para uma identidade docente específica, relacionada à matemática. Os termos para esse tipo de perfil identitário variam conforme distintas concepções. Por exemplo, Kaasila et al. (2008) e Lutovac e Kaasila (2014) usaram o termo "identidade matemática” para se referir a professores em formação inicial em matemática. Van Putten, Stols e Howie (2014) definiram identidade profissional do professor de matemática para se referirem àqueles que têm graduação na área e se encontram em serviço. Van Zoest e Bohl (2005), por sua vez, definiram identidade do professor de matemática para abranger aqueles que ensinam matemática, mas não têm graduação na área. Para Lutovac e Kaasila (2017), o termo mais adequado, dadas as diferenças entre professores que têm graduação em matemática, daqueles que apenas ensinam matemática, seja identidade do professor relacionada à matemática, de modo a incluir os dois grupos de professores.

Para tratarmos desse fator específico, usaremos o termo professor que ensina matemática no campo e nos basearemos, principalmente, nos estudos desenvolvidos por Sachs e Elias (2016), por representarem uns dos poucos estudos realizados sobre a formação Matemática nos cursos de Licenciatura em Educação do Campo em nível nacional.

Uma análise aos Projetos Político-Pedagógicos (PPP) de algumas dessas licenciaturas que ofertam habilitação em Matemática possibilitou perceber que o objetivo principal que se busca é uma articulação do saber matemático com a vida no campo. Se não, vejamos: 
[...] preparar educadores para uma atuação profissional que vá além da docência e dê conta da gestão dos processos educativos na escola e no seu entorno. Para isso, o curso deve tanto formar educadores para atuação específica junto às populações que trabalham e vivem no e do campo, como propiciar as bases de organização do trabalho escolar e pedagógico, a partir de estratégias de formação para a docência multidisciplinar em uma organização curricular por área do conhecimento. (UNIVERSIDADE FEDERAL DO SUL E SUDESTE DO PARÁ, 2014, p. 24).

[...] formar professores para a docência, num currículo que combina os saberes da área do conhecimento profissional com o campo da educação na perspectiva de atuação nas escolas situadas no campo ou que atendam as populações que se deslocam da mesma. (UNIVERSIDADE FEDERAL DE MINAS GERAIS, 2011, p. 10).

Assim como os saberes que dizem respeito ao fazer pedagógico e didático, construindo uma formação acadêmica e científica articulada com os saberes advindos do campo. (INSTITUTO FEDERAL FARROUPILHA, 2012, p. 18).

[...] possuir uma sólida formação teórico-prática nas seguintes áreas do conhecimento: ciências naturais, matemática, linguagem que lhes possibilitem associar os conteúdos curriculares e os saberes da experiência à necessidade e realidade do campo (UNIVERSIDADE FEDERAL DO PARÁ, 2009, p. 21).

Nota-se que tais cursos almejam uma formação que estude e problematize práticas sociais em uma perspectiva multidisciplinar capaz de promover articulações entre a academia e os saberes advindos do campo. Esse tipo de proposição difere de uma formação matemática em nível de Licenciatura em Matemática, por exemplo, onde a ênfase no contexto e no saber social não tem tanta notoriedade.

Além disso, estão consonantes ao parecer CNE/CEB 36/2001 e a resolução CNE/ CEB 1/2002 (BRASIL, 2001, 2002) que instituiu as Diretrizes Operacionais para a Educação Básica nas Escolas do Campo. No artigo 5. ${ }^{\circ}$ do último documento, por exemplo, afere-se sobre a importância de se considerar a "realidade dos sujeitos como princípio e fim da prática pedagógica” (BRASIL, 2002, p. 1). De igual modo, sinaliza em seu artigo 13, para o efetivo protagonismo de crianças, jovens e adultos na construção da qualidade social de vida individual e coletiva, considerando a diversidade do campo em todos os seus aspectos sociais, políticos, culturais, econômicos, de gênero e geração - sendo possível realizá-lo em diferentes espaços pedagógicos e tempos de aprendizagem.

Sobre como essas proposições são mobilizadas nos componentes curriculares de Matemática na formação inicial de educadores do campo no Brasil, Sachs e Elias (2016) elencaram as ementas de oito cursos com PPP disponíveis online, verificando se essa articulação entre formação acadêmica e os saberes do campo se mostrava efetivo. O lugar da formação 
matemática também foi objeto de interesse por parte de Sachs e Elias (2016) no sentido de verificar qual perspectiva matemática era recorrente nesse processo formativo: se uma matemática científica (ou acadêmica), entendida como "[...] um corpo científico de conhecimentos, segundo a produzem e a percebem os matemáticos profissionais" (MOREIRA; DAVID, 2010 apud SACHS; ELIAS, 2016, p. 442) ou uma matemática escolar, referindo-se ao conjunto de saberes “[...] 'validados', associados especificamente ao desenvolvimento do processo de educação escolar básica em Matemática.” (MOREIRA; DAVID, 2010 apud SACHS; ELIAS, 2016, p. 442).

Os autores concluíram que, de modo geral, predomina-se uma formação matemática científica em detrimento de uma matemática escolar. De igual modo, na maioria dos casos, as disciplinas de conteúdo matemático são dissociadas do contexto social do campo. Embora o contexto social camponês conste nos objetivos e perfil de egresso no que se refere às ementas dos componentes curriculares, esse aspecto não se mostrou evidente.

Há uma necessidade de uma formação científica, didática e política que precisa ser estabelecida em um tempo de aprendizagem relativamente curto nos espaços da universidade e são determinantes para se alcançar os objetivos pretendidos para esse perfil de professor. De modo geral, o fator matemático, no contexto da formação inicial de professores que ensinam matemática no campo ainda carece de ajustes para que se consiga promover os objetivos pedagógicos dessas licenciaturas; contudo, é importante fortalecer uma linguagem matemática que dê conta de conceitos matemáticos, seja integrativa com outras áreas de conhecimento e crítica o suficiente para se intervir pedagógica e politicamente nas comunidades rurais.

\section{Conclusão}

Objetivou-se discutir sobre a constituição da identidade formativa do futuro professor de Matemática para escolas do campo, elegendo fatores considerados interferentes nessa identidade, tais como: fator formativo (ou institucional), fator contextual, fator sociopolítico e fator matemático. Foram consultados documentos e outros materiais publicados sobre as Licenciaturas em Educação do Campo no Brasil para revelar características próprias da formação inicial desses professores e outras, gerais, possibilitando estabelecer distintas compreensões sobre elas - na ótica conceitual da identidade docente.

O fator formativo (ou institucional) estabeleceu uma contextualização acerca de como está ocorrendo a formação inicial de professores de matemática para escolas rurais em IES. Essas licenciaturas diferem do observado em outras graduações de professores, sendo embasadas em uma perspectiva de alternância pedagógica, representando, desse modo, uma configuração formativa particular. Conforme elucidado em nossas análises, o curso é estruturado em princípios de multidisciplinaridade, construção de pesquisas socioeducacionais e relações integrativas entre o contexto e vida campesina e os conhecimentos acadêmicos.

No âmbito da discussão sobre identidade docente, podemos situar o fator formativo das Licenciaturas em Educação do Campo como constitutivo de uma identidade institucional, uma vez que está centrado “em leis, regras, tradições e princípios” próprios (GEE, 2000, p. 102, tradução nossa), como os mencionados anteriormente, conduzindo a uma formação multidisciplinar e peculiar em seus modos de organização; além disso, é constitutivo de uma 
identidade por afinidade, relacionada ao "acesso e participação em práticas específicas que fornecem experiências necessárias a cada um dos membros do grupo” (GEE, 2000, p. 105, tradução nossa), como as pesquisas socioeducacionais e os processos de alternância pedagógica - esta última capaz de estabelecer interações constantes entre teoria (tempo universidade) e prática (tempo comunidade).

O fator contextual (escolar, principalmente) envolveu a compreensão acerca dos espaços e tempos onde os futuros professores do campo atuarão. Distintos estudos vêm mostrando a influência do contexto de trabalho na constituição identitária do professor (HOBBS, 2012; LUTOVAC; KAASILA, 2014; OWENS, 2014). Conforme sinalizado em nossas análises, o contexto de trabalho de quem ensina no campo perpassa, entre outros casos, por uma organização escolar multissérie, por tempos e espaços de ensino limitados e deficitários e por um currículo conflituoso entre aquilo que se espera para escolas rurais e o que se é praticado.

De modo geral, o fator contextual - inserido no processo formativo das Licenciaturas em Educação do Campo a partir dos estágios e das pesquisas socioeducacionais realizadas nas comunidades rurais - pode vir a interferir nessa identidade formativa, impactando, por exemplo, no que se entende sobre os papéis, os valores e as futuras ações pedagógicas do professor que ensinará matemática no campo. Novamente, a alternância pedagógica, como estrutura formativa típica dessas licenciaturas, tem implicações basilares na constituição identitária do futuro professor de matemática da zona rural. Isso porque a alternância pedagógica pressupõe uma mudança constante de contextos (ora acadêmicos, ora comunitários), de modo que tal dinâmica modela práticas e entendimentos do que é ser professor nos contextos campesinos.

O fator sociopolítico procurou destacar como as lutas sociais travadas nos territórios rurais impactam o ato pedagógico e, quando trazidas para serem problematizadas nos cursos de Licenciatura em Educação do Campo, também têm impactos na identidade formativa dos futuros professores. Ao se interligar de maneira dinâmica e dialética as disciplinas e os seminários temáticos do curso com discussões políticas e socioculturais do território camponês, tais licenciaturas promovem, nos termos de Gee (2000), uma identidade discursiva, podendo fomentar nos licenciandos um discurso que preza não somente pelo ensino, mas também pela militância política. Em síntese, nota-se, a partir dos documentos que direcionam essas licenciaturas, incluindo seus projetos político-pedagógicos, uma forte aderência ao fator sociopolítico na constituição da identidade formativa desses professores, capaz de gerar uma identidade discursiva, fortemente influenciada pelas relações constantes entre a universidade e a comunidade rural.

O fator matemático buscou destacar como a relação dos futuros professores que atuarão no campo com os conhecimentos escolares e curriculares de matemática influenciam sua identidade formativa. Baseado em Sachs e Elias (2016), um dos poucos estudos que investigou a formação matemática nos cursos de Licenciatura em Educação do Campo no Brasil, percebe-se que a matemática promovida em seus currículos diz respeito a uma matemática acadêmica, entretanto, com concepções de interligação com contextos sociais do campo e com a educação básica. A formação matemática do professor na educação do campo deve ser também para atender a carência no domínio dos objetos matemáticos a serem ensinados, levando em apreço as condições e restrições políticas, pedagógicas e principalmente didáticas relativas ao saber matemático para as instituições escolares dos espaços rurais. Poucas experiências práticas, em termos de materiais e relatórios didáticos, estão disponíveis e sistematizados para mostrar 
como o tripé educação matemática, contexto social do campo e formação docente podem se relacionar, destacando-se a necessidade de divulgações nesse sentido.

Nosso estudo buscou estabelecer, a partir da literatura sobre identidade docente e da estrutura formativa das Licenciaturas em Educação do Campo no Brasil, categorias de análise para se avaliar quais fatores impactam a identidade desse professor em formação. Esperamos que tais reflexões auxiliem a comunidade científica na projeção de programas e ações formativas a partir daquilo que entendemos ser fatores-chave na constituição do ser professor no campo. Pesquisas futuras podem ampliar essa perspectiva e enfatizar de modo mais proeminente que fatores, além dos que foram evidenciados, podem influenciar a identidade do professor em serviço. Trata-se de um caminho ainda em aberto e que merece maior atenção por parte dos pesquisadores.

\section{Referências}

ANTUNES-ROCHA, M. I. Licenciatura em educação do campo: histórico e projeto político-pedagógico. In: ANTUNES-ROCHA, M. I.; MARTINS, A. A. Educação do campo: desafios para a formação de professores. São Paulo: Autêntica, 2009. p. 39-56.

BEAUCHAMP, C.; THOMAS, L. Understanding teacher identity: an overview of issues in the literature and implications for teacher education. Cambridge Journal of Education, Abingdon, v. 39, n. 2, p. 175-189, 2009.

BEIJAARD, D.; MEIJER, P. C.; VERLOOP, N. Reconsidering research on teachers' professional identity. Teaching and Teacher Education, Oxford, v. 20, n. 2, p. 107-128, 2004.

BENNISON, A. Developing an analytic lens for investigating identity as an embedder-ofnumeracy. Mathematics Education Research Journal, Dordrecht, v. 27, n. 1, p. 1-19, 2015.

BRASIL. Ministério da Educação. Programa escola ativa: projeto base. Brasilia: MEC, 2008.

BRASIL. Conselho Nacional de Educação. Resolução CNE/CEB 1, de 3 de abril de 2002. Institui diretrizes operacionais para a educação básica nas escolas do campo. Brasília: CNE, 2002. Disponível em: http://pronacampo.mec.gov.br/images/pdf/mn_ resolucao_\%201_de_3_de_abril_de_2002.pdf. Acesso em: 1 jun. 2018.

BRASIL. Conselho Nacional de Educação. Diretrizes operacionais para a educação básica nas escolas do campo. Brasília: CNE, 2001. Disponível em: http:/ / portal.mec.gov. br/cne/arquivos/pdf/EducCampo01.pdf. Acesso em: 1 jun. 2018.

CATTLEY, G. Emergence of professional identity for the preservice teacher. International Education Journal, Murdoch, v. 8, n. 2, p. 337-347, 2007. 
CHEVRIER, J.; GOHIER, C.; ANADON, M.; GODBOUT, S. Construction de l'identité professionnelle des futures enseignantes: dispositifs de formation présents et souhaités selon les acteurs responsables de la formation des maitres au préscolaires et au primaire. In: GOHIER, C. (ed.). Identités professionnelles d'acteurs de l'enseignement. Québec: Presses de l'Université du Québec, 2007. p. 137-168.

CONNELLY, M.; CLANDININ, J. Shaping a professional identity: stories of educational practice. London: The Althouse Press, 1999.

DRAKE, C.; SPILLANE, J. P.; HUFFERD-ACKLES, K. Storied identities: teacher learning and subject-matter context. Journal of Curriculum Studies, Abingdon, v. 33, n. 1, p. 1-23, 2001. DOI: https://doi.org/10.1080/00220270119765.

ESSIEN, A. A. Examining opportunities for the development of interacting identities within pre servisse teacher education mathematics classrooms. Perspectives in Education, Bloemfontein, v. 32, n. 3, 62-77, 2014.

FREITAS, E. Troubling teacher identity: preparing mathematics teachers to teach for diversity. Teaching Education, Abingdon, v. 19, n. 1, p. 43-55, 2008.

GEE, J. P. Identity as an analytic lens for research in education. Review of Research in Education, Thousand Oaks, n. 25, p. 99-125, 2000.

GOOS, M. E.; BENNISON, A. Developing a communal identity as beginning teachers of mathematics: emergence of an online community of practice. Journal of Mathematics Teacher Education, Dordrecht, v. 11, n. 1, p. 41-60, 2008.

HARALAMBOS, M.; HOLBORN, M. Sociology: themes and perspectives. 5. ed. London: Collins Educational, 2000.

HOBBS, L. Teaching 'out-of-field' as a boundary-crossing event: factors shaping teacher identity. International Journal of Science and Mathematics Education, Dordrecht, v. 11, n. 2, p. 271-297, 2012.

HODGEN, J.; ASKEW, M. Emotion, identity, and teacher learning: becoming a primary mathematics teacher. Oxford Review of Education, Abingdon, v. 33, n. 4, p. 469-487, 2007.

HODGES, T. E.; CADY, J. A. Negotiating contexts to construct an identity as a mathematics teacher. Journal of Educational Research, Philadelphia, v. 105, n. 2, p. 112-122, 2012.

HUNT, C. Travels with a turtle: metaphors and the making of a professional identity.

Reflective Practice, Abingdon, v. 7, n. 3, p. 315-332, 2006.

INEP. Panorama da educação no campo. Brasília: INEP, 2007.

INSTITUTO FEDERAL FARROUPILHA. Projeto pedagógico do curso licenciatura em educação do campo. Jaguari: IFF, 2012. Disponível em: http://www.ja.iffarroupilha. edu.br/site/midias/arquivos/2013719141850268ppc_jaguari-_licenciatura_do_campo.pdf. Acesso em: 23 out. 2019. 
Silva, M. G. M.; Gonçalves, T. O.; Assunção, C. A. G.

JOHNSTON, D. H. "Sitting alone in the staffroom contemplating my future": communities of practice, legitimate peripheral participation and student teachers' experiences of problematic school placements as guests. Cambridge Journal of Education, Abingdon, v. 46, n. 4, p. 533-551, 2015.

KAASILA, R.; HANNULA, M.; LAINE, A.; PEHKONEN, E. Socio-emotional orientations and teacher change. Educational Studies in Mathematics, Dordrecht, v. 67, n. 2, p. 111-123, 2008.

KASTEN, S. E.; AUSTIN, C.; JACKSON, C. Am I a mathematics teacher who teaches middle grades or a middle grades teacher who teaches mathematics? Untangling the multiple identities of pre-service teachers. Middle Grades Research Journal, Charlotte, v. 9, n. 2, p. 127-140, 2014.

LEATHAM, K. R.; HILL, D. S. Exploring our complex math identities. Mathematics Teaching in the Middle School, Reston, v. 16, n. 4, p. 224-231, 2010.

LEAVY, A. M.; MCSORLEY, F. A.; BOTE, L. A. An examination of what metaphor construction reveals about the evolution of preservice teachers' beliefs about teaching and learning. Teaching and Teacher Education, Oxford, v. 23, n. 7, p. 1217-1233, 2007.

LUTOVAC, S.; KAASILA, R. Dialogue between past and future mathematical identities. Nordic Studies in Mathematics Education, Goeteborg, v. 17, n. 3-4, p. 125-139, 2012.

LUTOVAC, S.; KAASILA, R. Pre-service teachers' future-oriented mathematical identity work. Educational Studies in Mathematics, Dordrecht, v. 85, n. 1, p. 129-142, 2014.

LUTOVAC, S.; KAASILA, R. Future directions in research on mathematics-related teacher identity. International Jornal of Scince and Mathematics Education, Dordrecht, v. 16, n. 4, p. 759-776, 2017.

MITCHELL, C.; WEBER, S. Reinventing ourselves as teachers: beyond nostalgia. London: Routledge Falmer, 1999.

MORAES, R.; GALIAZZI, M. C. Análise textual discursiva. Ijuí: Editora Unijuí, 2011.

OWENS, K. The impact of a teacher education culture-based project on identity as a mathematically thinking teacher. Asia-Pacific Journal of Teacher Education, Melbourne, v. 42, n. 2, p. 186-207, 2014.

SACHS, L.; ELIAS, H. R. A formação matemática nos cursos de licenciatura em educação do campo. Bolema, Rio Claro, v. 30, n. 55, p. 439-454, 2016.

SFARD, A.; PRUSAK, A. Telling identities: in search of an analytic tool for investigating learning as a culturally shaped activity. Educational Researcher, Thousand Oaks, v. 34, n. 4, p. 14-22, 2005.

UNIVERSIDADE FEDERAL DO SUL E SUDESTE DO PARÁ. Projeto pedagógico do curso licenciatura em educação do campo. Marabá: UNIFESSPA, 2014. Disponível em: https://fecampo.unifesspa.edu.br/images/arquivos/PPC-EDUCAO-DO-CAMPO_2014. pdf. Acesso em: 23 out. 2019. 
UNIVERSIDADE FEDERAL DE MINAS GERAIS. Projeto pedagógico do curso licenciatura em Educação do Campo. Belo Horizonte: UFMG, 2011. Disponível em: https://www.fae.ufmg.br/cursos-graduacao. Acesso em: 23 out. 2019.

UNIVERSIDADE FEDERAL DO PARÁ. Projeto político-pedagógico: curso de licenciatura plena em educação do campo. Abaetetuba: UFPA, 2009. Disponível em: http://fadecam.ufpa.br/images/anexos/Projeto\%20Pedag\%C3\%B3gico\%202015.pdf . Acesso em: 23 out. 2019.

VAN PUTTEN, S.; STOLS, G.; HOWIE, S. Do prospective mathematics teachers teach who they say they are? Journal of Mathematics Teacher Education, Dordrecht, v. 17, n. 4, p. 369-392, 2014.

VAN ZOEST, L. R.; BOHL, J. V. Mathematics teacher identity: a framework for understanding secondary school mathematics teachers' learning through practice. Teacher Development, Abingdon, v. 9, n. 3, p. 315-345, 2005.

WENGER, E. Communities of practice: learning, meaning, and identity. Cambridge: Cambridge University Press, 1998. 
